\title{
Electronic Structure of the Cesium Oxide Molecule CsO
}

\author{
Diana Kaeen ${ }^{1}$, Mahmoud Korek ${ }^{\mathbf{*}}$, Saleh Nabhan Abdulal ${ }^{2}$ \\ ${ }^{1}$ Physics Department, Faculty of Science, Beirut Arab University, Beirut, Lebanon \\ ${ }^{2}$ Physics Department, Lebanese International University, Beirut, Lebanon \\ Email: fkorek@yahoo.com, ${ }^{*}$ mahmoud.korek@bau.edu.lb
}

Received 28 July 2015; accepted 25 October 2015; published 29 October 2015

Copyright (C) 2015 by authors and Scientific Research Publishing Inc.

This work is licensed under the Creative Commons Attribution International License (CC BY).

http://creativecommons.org/licenses/by/4.0/

(c) (i) Open Access

\begin{abstract}
Adiabatic potential energy curves of 12 doublet and quartet lowest spinless electronic states of the molecule CsO have been investigated via $a b$ initio CASSCF and MRCI (doublet and quartet excitations with Davidson correction) calculations. The spectroscopic constants such as vibrational harmonic frequency $\omega_{e}$, the internuclear distance at equilibrium $R_{e}$, the rotational constant $B_{e}$, and the electronic transition energy $T_{e}$ of the ground and the excited electronic states have been calculated by fitting the energy values around the equilibrium position to a polynomial in terms of the internuclear distance. The comparison of these values to those available in the literature shows a good agreement.
\end{abstract}

\section{Keywords}

ab Initio Calculation, CsO Molecule, Potential Energy Curves, Spectroscopic Constants

\section{Introduction}

The alkali metal oxides have been the subject of different theoretical and experimental studies in order to specify their electronic ground state. These studies focused on the transition between the 2 electronic states ${ }^{2} \Pi$ and ${ }^{2} \Sigma^{+}$ [1]-[3]. This change in ground state symmetry is due to the hole in oxygen that will lead either to a ${ }^{2} \Pi$ ( $\mathrm{LiO}^{2}$ and $\mathrm{NaO}$ ) or to a ${ }^{2} \Sigma^{+}$(KO, RbO and $\left.\mathrm{CsO}\right)$. The nature of ground state depends on the competing effects. When the terms are attractive, we expect to have ${ }^{2} \Pi$ as ground state due to quadrupole interactions while we expect to have ${ }^{2} \Sigma^{+}$as ground state due to Pauli repulsion. There is a great concern in studying the spectra of this molecule which is shown in different papers written on its ground state ${ }^{2} \Pi$ and the first excited state ${ }^{2} \Pi$. Using an $a b$ initio

"Corresponding author. 
method, Langhoff et al. [4] studied the ground states of alkali oxides and determined the values of spectroscopic constants for the two states ${ }^{2} \Sigma^{+}$and ${ }^{2} \Pi$. Lindsay et al. [5] demonstrated that $\mathrm{CsO}$ had ${ }^{2} \Sigma^{+}$ground state by using ESR matrix experiments. Allison and Goddard III [2] explained the change in ground state symmetry from LiO $\left({ }^{2} \Pi\right)$ to $\mathrm{CsO}\left({ }^{2} \Sigma^{+}\right)$. Yamada and Hirota [6] investigated systematically CsO by using microwave and infrared diode laser spectroscopy. The observed spectra showed that the ground state of $\mathrm{CsO}$ was ${ }^{2} \Sigma^{+}$. Woodward et al. [7] showed that the ground state of $\mathrm{CsO}$ was ${ }^{2} \Sigma^{+}$. It was demonstrated that $\mathrm{RbO}$ and $\mathrm{CsO}$ had ${ }^{2} \Sigma^{+}$ground states using ESR experiments [2] [5] which was indicated previously for $\mathrm{CsO}$ through reactive scattering experiments [8]. By using a high-level RCCSD(T) ab initio method, Lee et al. [9] calculated the spectroscopic constants of the two lying electronic states ${ }^{2} \Sigma^{+}$and ${ }^{2} \Pi$.

In the present work 12 low-lying doublet and quartet electronic states of $\mathrm{CsO}$ molecule have been investigated by using the $a b$ initio method. The potential energy curves (PECs) together with the transition energy with respect to the minimum energy for the ground state $T_{e}$, the equilibrium internuclear distance $R_{e}$, the harmonic frequency $\omega_{\mathrm{e}}$, and the rotational constant $\mathrm{B}_{\mathrm{e}}$ have been obtained for the considered electronic states. Ten electronic states have been investigated here for the first time.

\section{Method of Calculations}

In the present work we study the low-lying doublet and quartet electronic states of the molecule CsO using state averaged complete active space self consistent field (CASSCF) procedure followed by a multireference configuration interaction (MRDSCI with Davidson correction) treatment for the electron correlation. The entire CASSCF configuration space was used as the reference in the MRDSCI calculations, which were done via the computational chemistry program MOLPRO [10] taking advantage of the graphical user interface GABEDIT [11]. For this purpose five different basis sets were used in our theoretical study for cesium monoxide molecule. In the first basis set the 55 electrons of the cesium atom are considered using a contracted ECP46MWB basis set for $\mathrm{s}$ and $\mathrm{p}$ functions, while the oxygen species is treated as a system of 8 electrons by using the aug-cc-pCV5Z basis set for $\mathrm{s}, \mathrm{p}$, and d functions. In the second basis set, the 55 electrons of the cesium atom are considered using a contracted ECP46MWB basis set for $s$ and $p$ functions, while the oxygen species is treated as a system of 8 electrons by using the $6-311++\mathrm{G} * *$ basis set for $\mathrm{s}$, $\mathrm{p}$, and $\mathrm{d}$ functions. This basis is developed by optimizing exponents and coefficients at the Möller-Plesset second-order level. It has a triple split in the valence $s$ and $p$ shells together with a single set of uncontracted polarization functions on each atom. In the third basis set, the 55 electrons of the cesium atom are considered using a contracted Hay-Wadt VDZ $(n+1)$ ECP basis set for $\mathrm{s}$ and $\mathrm{p}$ functions, while the oxygen species is treated as a system of 8 electrons by using the aug-cc-pCV5Z basis set for $\mathrm{s}, \mathrm{p}$, and $\mathrm{d}$ functions.

In the fourth basis set the 55 electrons of the cesium atom are considered using a contracted ECP46MWB basis set for $\mathrm{s}$ and $\mathrm{p}$ functions, while the oxygen species is treated as a system of 8 electrons by using the VDZ basis set for $\mathrm{s}, \mathrm{p}$, and $\mathrm{d}$ functions. In the fifth basis set, the 55 electrons of the cesium atom are considered using a contracted ECP46MWB basis set for $\mathrm{s}$ and $\mathrm{p}$ functions, while the oxygen species is treated as a system of 8 electrons by using the aug-cc-pCVDZ basis set for s, p, and d functions.

Among the 63 electrons explicitly considered for CsO (55 electrons for Cs and 8 for O) 46 inner electrons were frozen in subsequent calculations so that 17 valence electrons were explicitly treated. All computations were performed in the $\mathrm{C}_{2 v}$ point group. Using the first basis set ECP46MWB, the potential energy curves of 12 low-lying electronic states of the molecule $\mathrm{CsO}$ were generated using the MRSDCI for 350 internuclear distances calculations in the range $1.5 \AA \leq \mathrm{R}_{\mathrm{e}} \leq 5 \AA$ in the representation ${ }^{2 \mathrm{~s}+1} \Lambda^{( \pm)}$where we assumed that, the CsO molecule is mainly ionic around the equilibrium position. These PECs for the different symmetries are given in Figure 1 and Figure 2.

The spectroscopic constant $\omega_{\mathrm{e}}, \mathrm{r}_{\mathrm{e}}, \mathrm{B}_{\mathrm{e}}$, and $\mathrm{T}_{\mathrm{e}}$ have been calculated by fitting the energy values around the equilibrium position to a polynomial in terms of the internuclear distance. These values are given in Table 1 with the available values in the literature. The comparison of our results for the constants $\omega_{\mathrm{e}}$ with those available in literature [3] [4] [6] [9] [12] [13] shows a very good agreement by using the second basis for the states $\mathrm{X}^{2} \Sigma^{+}$ with the relative difference $2.6 \%$ ([4]) $\leq \Delta \omega_{\mathrm{e}} / \omega_{\mathrm{e}} \leq 4.4 \%$ ([9]); while the best agreement for the state $(1)^{2} \Pi$ is obtained by using the basis one with the relative difference $4.8 \%$ ([12]) $\leq \Delta \omega_{\mathrm{e}} / \omega_{\mathrm{e}} \leq 6.8 \%$ ([4]). By comparing our calculated values of $R_{e}$ with those found in literature for the 2 electronic states $X^{2} \Sigma^{+}$and $(1)^{2} \Pi$, one can find an 


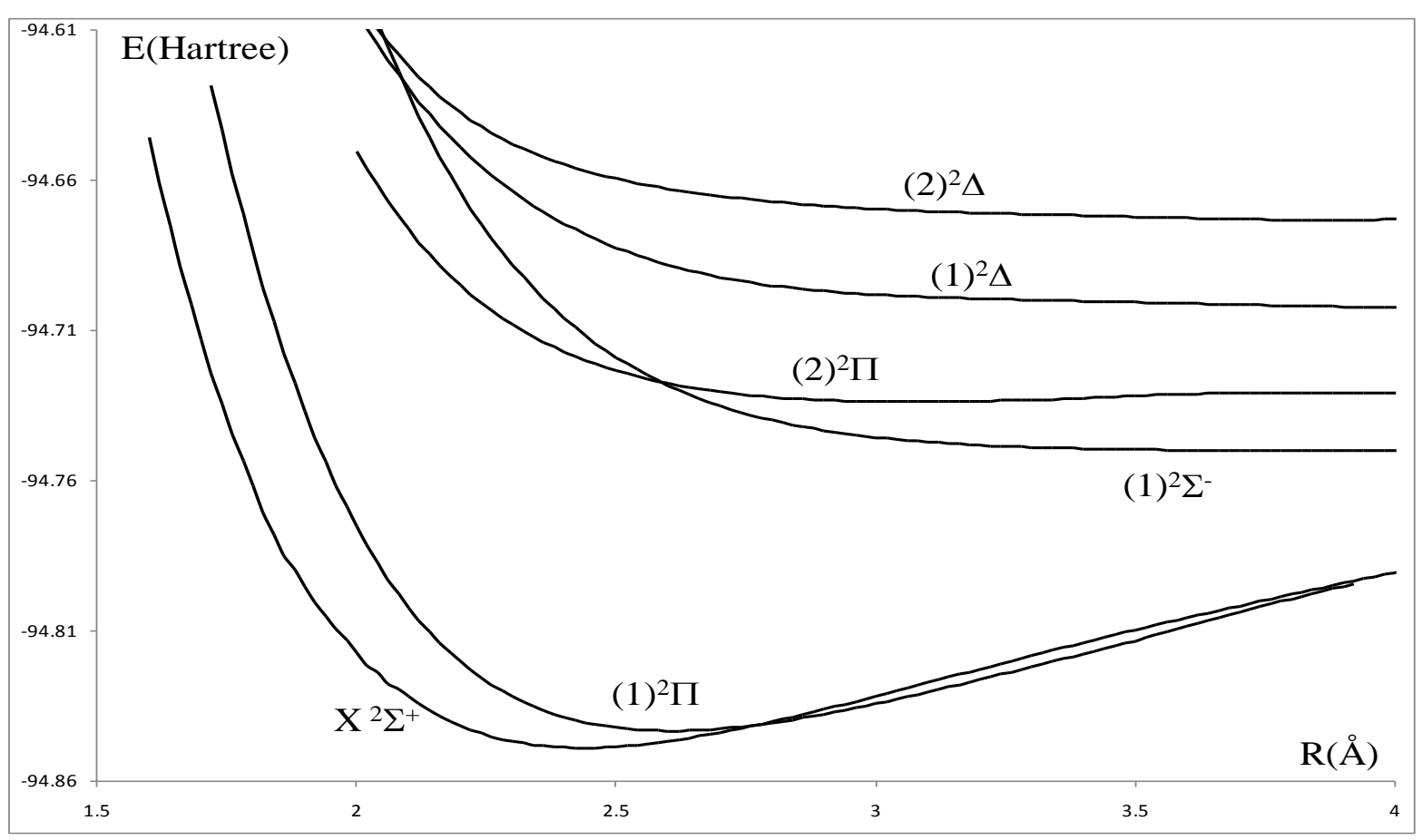

Figure 1. Potential energy curves of the lowest doublet electronic states of the molecule CsO using the first basis set.

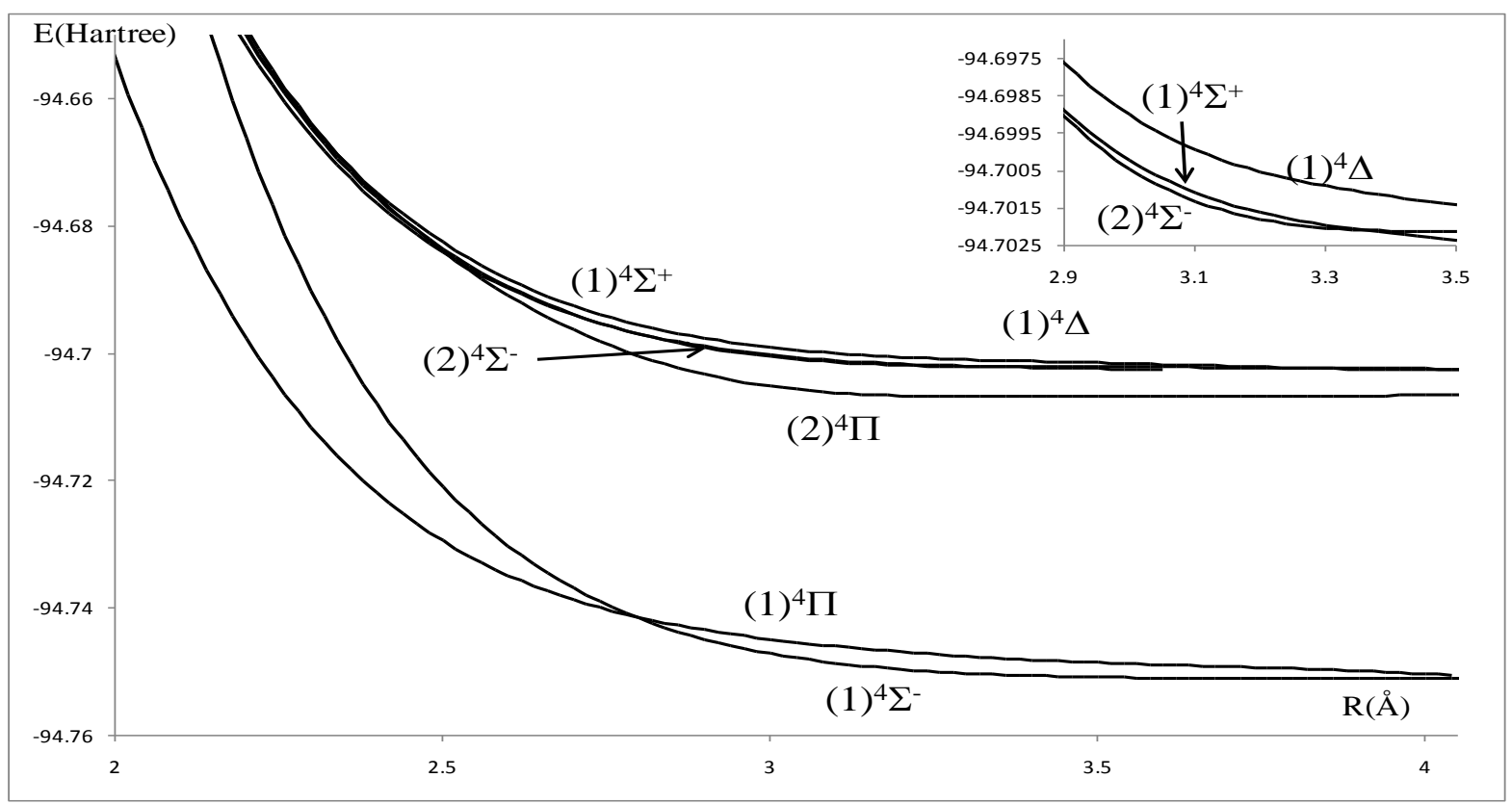

Figure 2. Potential energy curves of the lowest quartet electronic states of the molecule CsO using the first basis set.

excellent agreement is obtained by using the first, fourth and fifth used basis sets with the relative differences $0.32 \%([12]) \leq \Delta \mathrm{R}_{\mathrm{e}} / \mathrm{R}_{\mathrm{e}} \leq 0.37 \%([4])$.

Our calculated values of $\mathrm{T}_{\mathrm{e}}$ by using basis one are in very good agreement with those given in [4] [6] [9] with the relative differences $1.04 \%$ ([6]) $\leq \Delta \mathrm{T}_{\mathrm{e}} / \mathrm{T}_{\mathrm{e}} \leq 6.1 \%$ ([9]). This agreement deteriorates by using third and fifth basis sets. There is no comparison of our calculated values for $\mathrm{B}_{\mathrm{e}}$ and for the investigated spectroscopic constants of the electronic states $(1)^{4} \Sigma^{-},(2)^{2} \Pi,(2)^{4} \Sigma^{-}$since they are given here for the first time. These spectroscopic constants are also absent for other investigated electronic states either because of the crossing or avoiding 
Table 1. Spectroscopic constants for the lowest doublet and quartet electronic states of the molecule CsO.

\begin{tabular}{|c|c|c|c|c|c|c|c|}
\hline States & $\mathrm{T}_{\mathrm{e}}\left(\mathrm{cm}^{-1}\right)$ & $\delta \mathrm{T}_{\mathrm{e}} / \mathrm{T}_{\mathrm{e}} \%$ & $\omega_{\mathrm{e}} \times 10^{3}\left(\mathrm{~cm}^{-1}\right)$ & $\delta \omega_{\mathrm{e}} / \omega_{\mathrm{e}} \%$ & $\mathrm{R}_{\mathrm{e}}(\AA)$ & $\delta \mathrm{R}_{\mathrm{e}} / \mathrm{R}_{\mathrm{e}} \%$ & $\mathrm{~B}_{\mathrm{e}}\left(\mathrm{cm}^{-1}\right)$ \\
\hline \multirow[t]{10}{*}{$\mathrm{X}^{2} \Sigma^{+}$} & 0 & & $0.323^{(\mathrm{a})}$ & & $2.434^{(\mathrm{a})}$ & & $0.199^{(a)}$ \\
\hline & & & $0.325^{(\mathrm{b})}$ & & $2.561^{(\mathrm{b})}$ & & $0.179^{(b)}$ \\
\hline & & & $0.372^{(\mathrm{c})}$ & & $2.617^{(c)}$ & & $0.172^{(\mathrm{c})}$ \\
\hline & & & $0.31^{(\mathrm{d})}$ & & $2.5^{(\mathrm{d})}$ & & $0.188^{(\mathrm{d})}$ \\
\hline & & & $0.308^{(\mathrm{e})}$ & & $2.478^{(\mathrm{e})}$ & & $0.192^{(\mathrm{e})}$ \\
\hline & & & $0.334^{(\mathrm{f})}$ & $\begin{array}{c}3.2^{(\mathrm{a})} \\
2.6^{(\mathrm{b})} \\
11.3^{(\mathrm{c})} \\
7.1^{(\mathrm{d})} \\
7.7^{(\mathrm{e})}\end{array}$ & $2.425^{(\mathrm{f})}$ & $\begin{array}{c}0.37^{(\mathrm{a})} \\
5.6^{(\mathrm{b})} \\
7.9^{(\mathrm{c})} \\
3.0^{\text {(d) }} \\
2.1^{(\mathrm{e})}\end{array}$ & \\
\hline & & & & & $2.3^{(\mathrm{g})}$ & $\begin{array}{c}5.8^{(\mathrm{a})} \\
11.3^{(\mathrm{b})} \\
13.7^{(\mathrm{c})} \\
8.6^{(\mathrm{d})} \\
7.7^{(\mathrm{e})}\end{array}$ & \\
\hline & & & $0.34^{(\mathrm{h})}$ & $\begin{array}{c}5^{(\mathrm{a})} \\
4.4^{(\mathrm{b})} \\
9.4^{(\mathrm{c})} \\
8.8^{(\mathrm{d})} \\
9.4^{(\mathrm{e})}\end{array}$ & $2.337^{(\mathrm{h})}$ & $\begin{array}{c}4.1^{(\mathrm{a})} \\
9.5^{(\mathrm{b})} \\
11.9^{(\mathrm{c})} \\
6.9^{(\mathrm{d})} \\
6.03^{(\mathrm{e})}\end{array}$ & \\
\hline & & & & & $2.67^{(\mathrm{k})}$ & $\begin{array}{c}8.8^{(\mathrm{a})} \\
4.08^{(\mathrm{b})} \\
1.9^{(\mathrm{c})} \\
6.3^{(\mathrm{d})} \\
7.19^{(\mathrm{e})}\end{array}$ & \\
\hline & & & & & $2.47^{(1)}$ & $\begin{array}{l}1.45^{(\mathrm{a})} \\
3.68^{(\mathrm{b})} \\
5.95^{(\mathrm{c})} \\
1.21^{(\mathrm{d})} \\
0.32^{(\mathrm{e})}\end{array}$ & \\
\hline \multirow[t]{7}{*}{$(1)^{2} \Pi$} & $1237.77^{(\mathrm{a})}$ & & $0.297^{(\mathrm{a})}$ & & $2.604^{(\mathrm{a})}$ & & $0.174^{(\mathrm{a})}$ \\
\hline & $1644.8^{(\mathrm{c})}$ & & $0.403^{(\mathrm{c})}$ & & $2.78^{(\mathrm{c})}$ & & $0.152^{(\mathrm{c})}$ \\
\hline & $1606.22^{(\mathrm{e})}$ & & $0.27^{(\mathrm{e})}$ & & $2.672^{(\mathrm{e})}$ & & $0.165^{(\mathrm{e})}$ \\
\hline & $1225^{(\mathrm{g})}$ & $\begin{array}{c}1.04^{(\mathrm{a})} \\
34.2^{(\mathrm{c})} \\
31.12^{(\mathrm{e})}\end{array}$ & & & & & \\
\hline & $1100 \pm 200^{(i)}$ & $\begin{array}{c}4.7^{(\mathrm{a})} \\
26.5^{(\mathrm{c})} \\
23.5^{(\mathrm{e})}\end{array}$ & & & & & \\
\hline & $1319^{(\mathrm{h})}$ & $\begin{array}{c}6.1^{(\mathrm{a})} \\
24.7^{(\mathrm{c})} \\
21.7^{(\mathrm{e})}\end{array}$ & $0.324^{(\mathrm{h})}$ & $\begin{array}{c}8.3^{(\mathrm{a})} \\
24.3^{(\mathrm{c})} \\
16.6^{(\mathrm{e})}\end{array}$ & $2.526^{(\mathrm{h})}$ & $\begin{array}{c}3.08^{(\mathrm{a})} \\
10.05^{(\mathrm{c})} \\
5.7^{(\mathrm{e})}\end{array}$ & \\
\hline & & & $0.319^{(\mathrm{f})}$ & $\begin{array}{c}6.8^{(\mathrm{a})} \\
26.3^{(\mathrm{c})} \\
15.3^{(\mathrm{e})}\end{array}$ & $2.561^{(\mathrm{f})}$ & $\begin{array}{l}1.6^{(\mathrm{a})} \\
8.5^{(\mathrm{c})} \\
4.3^{(\mathrm{e})}\end{array}$ & \\
\hline
\end{tabular}




\section{Continued}

\begin{tabular}{|c|c|c|c|c|c|c|}
\hline & & $0.312^{(1)}$ & $\begin{array}{c}4.8^{(\mathrm{a})} \\
29.1^{(\mathrm{c})} \\
13.4^{(\mathrm{e})}\end{array}$ & $2.64^{(1)}$ & $\begin{array}{l}1.3^{(\mathrm{a})} \\
5.3^{(\mathrm{c})} \\
1.2^{(\mathrm{e})}\end{array}$ & \\
\hline$(1)^{4} \Sigma^{-}$ & $21503.33^{(a)}$ & $0.072^{(\mathrm{a})}$ & & $3.79^{(a)}$ & & $0.078^{(a)}$ \\
\hline$(2)^{2} \Pi$ & $25262.41^{(a)}$ & $0.092^{(\mathrm{a})}$ & & $3.066^{(\mathrm{a})}$ & & $0.125^{(a)}$ \\
\hline$(2)^{4} \Sigma^{-}$ & $32159.09^{(a)}$ & $0.179^{(a)}$ & & $3.425^{(\mathrm{a})}$ & & $0.172^{(a)}$ \\
\hline
\end{tabular}

${ }^{\mathrm{a}}$ Present work using for the 55 electrons of the cesium atom a contracted ECP46MWB basis set for $\mathrm{s}$ and p functions, while the oxygen species is treated as a system of 8 electrons by using the aug-cc-pCV5Z basis set for s, p, and d functions. ${ }^{\mathrm{b}}$ Present work using for the 55 electrons of the cesium atom a contracted ECP46MWB basis set for $\mathrm{s}$ and p functions , while the oxygen species is treated as a system of 8 electrons by using the 6-311++G** basis set for s, p, and d functions. ${ }^{\circ}$ Present work using for the 55 electrons of the cesium atom a contracted Hay-Wadt VDZ (n+1) ECP basis set for s and p functions, while the oxygen species is treated as a system of 8 electrons by using the aug-cc-pCV5Z basis set for s, p, and d functions. ${ }^{\mathrm{d}}$ Present work using for the 55 electrons of the cesium atom a contracted ECP46MWB basis set for $\mathrm{s}$ and p functions, while the oxygen species is treated as a system of 8 electrons by using the VDZ basis set for s, p, and d functions. ${ }^{e}$ Present work using for the 55 electrons of the cesium atom a contracted ECP46MWB basis set for $\mathrm{s}$ and p functions, while the oxygen species is treated as a system of 8 electrons by using the aug-cc-pCVDZ basis set for s, p, and d functions. ${ }^{\mathrm{R}}$ Ref. [3], ${ }^{\mathrm{R}}$ Ref. [4], ${ }^{\mathrm{g}}$ Ref. [6], ${ }^{\mathrm{h}}$ Ref. [9], ${ }^{\mathrm{l}}$ Ref. [12], ${ }^{\mathrm{i}}$ Ref. [13].

crossing near the minima of these states or they are unbound states.

\section{Conclusion}

In the present work, the $a b$ initio investigation for the low-lying doublet and quartet electronic states of the CsO molecule has been performed via CASSCF/MRCI method using five different basis sets. The potential energy curves have been determined along with the spectroscopic constants $T_{e}, R_{e}, \omega_{e}$ and the rotational constant $B_{e}$ for these states. The calculation has been done by using 5 different basis sets. The comparison of our results with those obtained theoretically in literature shows a very good accuracy. Ten new electronic states have been investigated in the present work for the first time.

\section{References}

[1] So, S.P. and Richards, W.G. (1975) The Electronic Ground States of Alkali Monoxides. Chemical Physics Letters, 32, 227-230. http://dx.doi.org/10.1016/0009-2614(75)85109-8

[2] Allison, J.N. and Goddard III, W.A. (1982) Alkali Oxide Diatomics: Explanation of the Change in Ground State Symmetry from $\left.\mathrm{LiO}\left({ }^{2} \Pi\right) \mathrm{CsO}^{2} \Sigma^{+}\right)$. The Journal of Chemical Physics, 77, 4259-4261. http://dx.doi.org/10.1063/1.444306

[3] Allison, J.N., Cave, R.J. and Goddard III, W.A. (1984) Alkali Oxides. Analysis of Bonding and Explanation of the Reversal in Ordering of the 2.PI. and 2.SIGMA. States. Journal of Physical Chemistry, 88, 1262-1268. http://dx.doi.org/10.1021/j150650a049

[4] Langhoff, S.R., Bauschlicher Jr., C.W. and Partdridge, H. (1986) Theoretical Study of the Diatomic Alkali and Alkaline-Earth Oxides. The Journal of Chemical Physics, 84, 4474-4480. http://dx.doi.org/10.1063/1.450019

[5] Lindsay, D.M., Herschbach, D.R. and Kwiram, A.L. (1974) ESR Spectra of Matrix Isolated CsO and RbO Molecules: ${ }^{2} \Sigma$ Ground States and Inner Shell Bonding. The Journal of Chemical Physics, 60, 315. http://dx.doi.org/10.1063/1.1680787

[6] Yamada, C. and Hirota, E. (1999) The Microwave Spectrum of the Cesium Monoxide CsO radical. The Journal of Chemical Physics, 111, 9587-9592. http://dx.doi.org/10.1063/1.480291

[7] Woodward, J.R., Hayden, J.S. and Gole, J.L. (1989) Formation and Characterization of a Low-Lying Electronic State of the Alkali Monoxides LiO...CsO in the Red and Near Infrared. Chemical Physics, 134, 395-419. http://dx.doi.org/10.1016/0301-0104(89)87171-X

[8] Herm, R.R. and Herschbach, D.R. (1970) Molecular Beam Kinetics: Reactions of Alkali Atoms with $\mathrm{NO}_{2}$ and $\mathrm{CH}_{3} \mathrm{NO}_{2}$. The Journal of Chemical Physics, 52, 5783. http://dx.doi.org/10.1063/1.1672860

[9] Lee, E.P.F., Lozeille, J., Soldan, P., Daire, S.E., Dyke, J.M. and Wright, T.G. (2001) An ab Initio Study of RbO, CsO and $\mathrm{FrO}\left(\mathrm{X}^{2} \Sigma^{+} ; \mathrm{A}^{2} \Pi\right)$ and their cations $\left(\mathrm{X}^{3} \Sigma^{-} ; \mathrm{A}^{3} \Pi\right)$. Physical Chemistry Chemical Physics, 3, 4863-4869. http://dx.doi.org/10.1039/b104835j

[10] Werner, H.J., Knowles, P.J., Lindh, R., Manby, F.R., Schütz, M., Celani, P., Korona, T., Rauhut, G., Amos, R.D., Bernhardsson, A., Berning, A., Cooper, D.L., Deegan, M.J.O., Dobbyn, A.J., Eckert, F., Hampel, C., Hetzer, G., Lloyd, 
A.W., McNicholas, S.J., Meyer, W., Mura, M.E., Nicklaß, A., Palmieri, P., Pitzer, R., Schumann, U., Stoll, H., Stone, A.J., Tarroni, R. and Thorsteinsson, T. (2009) MOLPRO Is a Package of ab Initio Programs.

[11] Allouche, A.R. (2011) Gabedit-A Graphical User Interface for Computational Chemistry Softwares. Journal of Computational Chemistry, 32, 174-182. http://dx.doi.org/10.1002/jcc.21600

[12] Laskowski, B.C. Langhoff., S.R. and Siegbahn, P.E.M. (1983) Theoretical Determination of the $X^{2} \Sigma^{+}$and $A^{2} \Pi$ Potentials of CsO Using Relativistic Effective Core Potentials. International Journal of Quantum Chemistry, 23, 483-490. http://dx.doi.org/10.1002/qua.560230218

[13] Sarkas, H.W., Kendricks, J.H., Arnold, S.T., Slager, V.L. and Bowen, K.H. (1994) Measurement of the $X^{2} \Sigma^{+}-A{ }^{2} \Pi$ Splitting in $\mathrm{CsO}$ via Photoelectron Spectroscopy of $\mathrm{CsO}^{-}$. The Journal of Chemical Physics, 100, 3358. http://dx.doi.org/10.1063/1.466428 